\title{
Perception of Turnitin: Checking Plagiarism among Staff at Koforidua Technical University (KTU), Ghana
}

\author{
Asante Edward ${ }^{1}$, Baayel Patrick ${ }^{2}$, Adjei Budu Kenneth Wilson ${ }^{3}$ and Owusu-Acheaw Michael ${ }^{4}$ \\ 1,2,3,4 Koforidua Technical University, Ghana \\ ${ }^{1}$ Correspondence: asante.edward@,ktu.edu.gh
}

\begin{abstract}
The study explored perceptions on the usage of Turnitin Plagiarism checking software among the staff of Koforidua Technical University (KTU) in Ghana. The research sought to explore the associations between the independent variables (Attitude and Perception, Perceived Challenges and Readiness to Use) and the dependent variable (System Usage) of the Turnitin Software among the staff of KTU. The survey adopted the quantitative research approach. Google forms were used to design questionnaires and mailed to the participants. The response rate valid for analysis was $98.7 \%$, against a sample size of 309 participants. SmartPLS3 software was used to explore the data extracted from google forms. The results of the convergent, discriminant validity calculation were all within the satisfactory threshold. Four hypothetical statements were tested, three of them showed significant association with the independent variables (Attitude and Perception, Perceived Challenges and Readiness to Use) and dependent variable (System Usage) except System Awareness which was not supported and rejected. The proposed model explained $66.7 \%$ invariance of the System Usage (Turnitin Software). The study recommends continuous dissemination of information about the availability of the Turnitin Software in the University.
\end{abstract}

Keywords: plagiarism checker, technical universities, attitude and perception, perceived challenges, readiness to use, system usage, system awareness

Citation: Asante, E., Baayel, P., Adjei, B., K.W., and Owusu-Acheaw, M. (2021). Perception of Turnitin: Checking Plagiarism among Staff at Koforidua Technical University (KTU), Ghana. International Journal of Technology and Management Research (IJTMR), Vol. 6 (1): Pp.116-128.

Received: March 20, 2021

Accepted: September 1, 2021 


\subsection{Introduction}

Turnitin is a widely known, and leading anti-plagiarism software, which is reported to have enjoyed widespread acceptance amongst academic researchers in about 135 countries, within 15,000 institutions, and amongst an estimated user population of about thirty million worldwide. The Turnitin plagiarism detection system allows academic researchers to upload their scholarly works with the results matched for similarities with web contents, as well as all other assignments uploaded by institutions using the system and certain journals. An online report is thus generated for each submission identifying the sources of those similarities and the percentage match. There is a significant benefit in using the Turnitin system for it allows for the identification of possible cases of plagiarism It thus guides academic researchers to conduct original research works to ensure academic and research integrity (Jones, 2008).

The Turnitin service developer (iParadigms LLC) in recent times has sought to provide improved service to enhance the user experience by introducing diverse student learning experiences aimed at improving students' learning outcomes. For instance, Turnitin (2017) has stated its introduction of new functions in ways to provide improved research and learning experience. Mohammadkarimi and Amin (2019), report, indicate that the introduction of new and improved service support systems has contributed to improved user experience and student learning and writing outcomes by about 77\% leading to higher institutional subscriptions to the software. For instance, the introduction of improved technical support service including the feedback studio service by Turnitin in 2017 has brought about significant improvement in user experience (Mohammadkarimi and Amin, 2019).

Rolfe (2011), also points out a significant improvement in students 'writing skills due to their use of the Turnitin plagiarism checking system. The originality report of students work produced from Turnitin might support the students in learning about ethical issues such as academic fraudulence (Zeman, Steen and Zeman, 2011). In addition, currently, almost all instructors are adopting Turnitin for online learning and marking. This has helped in providing more substantial responses, enhancing the learning process of students and saving the phase of students in learning (Turnitin, 2017).

Equally, the adoption of Turnitin has supported peer review periodicals and academia in noticing writers and students about the importance of plagiarism. As a result of the feedback from Turnitin students and writers are deterred from indulging in some sort of plagiarised activity. Using Turnitin at the same time adds up to and improves the writings skills of individuals in academia (Ali, 2013). Several kinds of anti-plagiarism software with different degrees of abilities and defectiveness exist. Common examples in the literature are Plagiarism Detect.com, PlagiServe, iThenticate, WCopyfind, Safe Assign, Viper, Digital books Web browsers, EduTie, Turnitin among others (Ali, 2013).

Plagiarism incidence in academic exploration is an unembellished delinquent (Ibegbulam and Eze 2015). In respect to that students and staff are not having considerable experience in philosophies of scholarly behaviour. This has resulted in the deficiency of academic morals and poor writing skills (Babalola, 2012; Ibegbulam \& Eze, 2015).

The rapid shift in the digital revolution and information and communication technologies (ICT) has brought about a massive transformation and availability as well as accessibility of information (Babalola, 2012; Ibegbulam \& Eze, 2015). Nowadays there is an enormous quantity of information available on different physical designs (Babalola, 
2012). This has prompted the risk of pilfering of the information in the academic environment. Generally, academic fraudulence occurs due to varied reasons ascribed by scholars (Ison, 2012; Onuoha and Ikonne, 2013). Some of the common reasons are inadequate knowledge, lack of awareness and attitude on plagiarism as well as the software. The discourse of this subject is of dynamic reasons which cause an occurrence of plagiarism in research as supported by (Ibegbulam and Eze, 2015; Onuoha and Ikonne, 2013).

In this regard, dishonesty among academics is the foremost rising anxiety for practically all stakeholders in the scholastic environment. The level of excellence and richness of enquiry is crucial for all levels of educational institutions particularly the tertiary institution to protect a good position among international standards (Ison, 2012; Onuoha and Ikonne, 2013). Research superiority openly brands the reputation of academic institutions (Ison, 2012; Onuoha and Ikonne, 2013). Academic research output and its quality is another issue that has fascinated the consideration of funding bodies, ranking agencies and governments over some time now (Ison, 2012; Onuoha and Ikonne, 2013).

Anney and Mosha (2015), explained that academia has ethical codes and policies for thieving recognition. Their findings show that most students had understood that plagiarism is academic dishonest, however, this has not stopped them from plagiarizing (Anney \& Mosha, 2015). The authors, in addition, posited that several factors not limited to "access to the internet, shortage of books, student's laziness and poor academic writing skills" played a key role in students' plagiarism.

Mohindra's (2019) study discovered that survey intellectual are mindful of lifting issues in academia. "Cut copypaste of text" was the top-ranked awareness statement whereas, the lowest awareness was detected with regards to the issue of "Collusion is helping someone else to plagiarise" (Mohindra, 2019). Again, it was noticed that plagiarism checking before submission of what wherever assignment, accurate reference list, and discussion with "colleagues" establish the uppermost steps which can be cooperative to enquirers in fading lifting (Mohindra, 2019). According to Ocholla and Ocholla (2016), "plagiarism is a predicament in higher education, however, it is no longer doubtful and has grown easier to expose".

In the view of Ramzan, Munir, Siddique and Asif (2012), research inquiry is an innovative and methodical enquiry undertaken to determine novel realities and information about a phenomenon. Notwithstanding such a brilliant resultant effect, a variety of empirical and ethical issues are on the rise in academia. It has become clear from the literature that the issue of plagiarism has become part of the worldwide education and research culture. But the challenge is that students and researchers are still turning to the open internet looking for information to support their research papers and thesis as well as shortcuts for writing assignments (Ramzan, et al, 2012).

Ramzan, et al. (2012), believe that there was a low level of awareness about plagiarism and university plagiarism policies and processes amongst the students. Ramzan, et al. (2012), bemoans that many respondents did not understand the term plagiarism. A significant number of students have fairly admitted that they have intentionally plagiarized written materials. Ramzan, et al. (2012), suggested that generating cognizance amongst the students regarding plagiarism, is of great significance. Again it was also established that proving plagiarism policy and statistical pieces of evidence for formulation of the policies and guidelines to fight plagiarism in academia is critical (Munir, et 
al. 2012). This was supported by Singh (2017), who concluded that there is a tall list of plagiarism offenders of learners in higher institutions.

Hosny and Fatima (2014), pointed out that duplicitous is common among students although conventional students appreciate the sense of bootlegging. Previous research by Gilomore et al. (2010), evaluated investigation proposals succumbed by learners at a university. The authors advanced that almost forty percent of the total suggestions involved illustrious plagiarism such as a reproduction of the transcript from websites and journals. Cheema et al. (2011), disclosed that most of the participants in a previous study are aware of the concept of plagiarism. However, not fully aware of the types and penalties of plagiarism.

Badalona's (2012), study discovered a positive significant association between plagiarism and levels of awareness. Ramzan et al. (2012), posited that "there was a lower indication on the level of awareness with regards to procedures and strategies of plagiarism amongst students in developing countries". This was supported by authors such as (Vanbaelen and Harrison, 2013; Kumari and Lakshmi, 2015; Ibegbulam and Eze, 2015), who claimed that communal students are aware of the rules in respect of plagiarism. Kumar and Mohindra (2018), are among the writers who argued that the perception and attitude of students to plagiarism is high. The authors concluded that it is a result of a deficiency of in-text expertise among students. The authors highlighted "fear of being scored poorly", awareness that other students were doing it, the opportunities for copying offered by the internet, and the absence of punishment for plagiarism related offences" as the foremost details overdue to the occurrence of plagiarism (Ibegbulam \& Eze, 2015).

Newton (2016), observed in a previous study that undergraduates were poised in their empathetic of plagiarism. Jereb et al. (2018), revealed that ICT has a significant impact on plagiarism. The authors comment that the review of numerous studies (Vanbaelen and Harrison, 2013; Kumari and Lakshmi, 2015; Ibegbulam and Eze, 2015), revealed episodes of acts of plagiarism by students in academia. It was also confirmed in the study of Jereb $e t$ al. (2018) that lack of awareness and poor academic assistance also roots plagiarism to a higher extent confirming the level of cheating among students. Brown and Janssen (2017), concluded that "plagiarism, cheating and academic integrity are on the ascendancy among students". The available works offer limited practical approaches on how to deal with the problem (Helgesson and Eriksson, 2015).

Rodchua (2017), echoed that "academic integrity is one of the fundamental values that institutions must commit to uphold and to promote". The number of university students who admit to cheating in some form is vast. This dishonest conduct is potential and can damage a university's reputation and students' learning experience (Rodchua, 2017). According to Ferro and Martins (2016), lying is universal when it comes to an academic exercise. Ferro and Martins (2016), further claimed that plagiarism is pervasive because people are used to lying to succeed.

According to Mohammadkarimi and Amin (2019), student's assessment is one of the essential apparatuses of education to appraise the efficiency of a programme. Mohammadkarimi and Amin (2019), posited that antiplagiarism software packages are widely used in many universities and institutions to assess students' performances in their assignments and papers (Mohammadkarimi \& Amin, 2019). In another view, Deubel (2018), brought to light that manual analysis, Google searches, and originality reports from Turnitin are critical elements of plagiarism. 
Deubel (2018), stressed that plagiarism prevention approaches are provided to exemplify the joint responsibility of a university, faculty, and students to prevent the occurrence of such issues.

Olutola (2016), posited that "the rate at which staff and students involve in various acts of plagiarism has been a matter of central concern to academics and university management at least over the last decades". There is not any qualm that academic dishonesty is a moral and ethical issue, but the lack of information, awareness and attitude also establishes plagiarism (Olutola, 2016). As elaborated above, several researchers (Olutola, 2016; Deubel, 2018; Rodchua, 2017; Newton, 2016; Ibegbulam and Eze, 2015) are among the writers who claimed that the usage of Turnitin in checking plagiarism is the source of academic dishonesty. However, no study has been conducted to ascertain the responsiveness and perception of the use of Turnitin in checking plagiarism among the staff of KTU since the university started using it. The current study, therefore, has been undertaken to explore the perception of the use of the Turnitin Software in checking plagiarism among staff at Koforidua Technical University (KTU), Ghana. The explicit objectives are:

- to observe the level of awareness of the Turnitin among staff at KTU

- to identify the attitudes and perception of staff at KTU towards plagiarism

- to identify the challenges staff, face in using the Turnitin in checking plagiarism

\subsection{Brief Profile of Koforidua Technical University (KTU), Ghana}

KTU over the time of its existence, has fashioned out different career-focused and practical-based manpower to support the country's developmental growth. KTU is located in the Eastern corridors of Ghana. KTU was given a new status in agreement with the Technical University Act 2016, (Act 922) in September 2016.

KTU since its inception, has grown in the context of programmes of study, faculties, student enrolment as well as infrastructural. KTU have five faculties and one institute of not more than eight thousand six hundred student's population. The faculties are applied science and technology (FAST), and health and allied science (FHAS), business and management studies (FBMS) and built and natural environment (FBNE). The faculties work hand in hand with the University Library in support of teaching and learning (Koforidua Technical University, 16th Congregation \& Investiture Ceremony, 2020).

As a university, KTU has thirteen Bachelor of Technology programmes. The university also has twenty Higher National Diploma programmes. Apart from the main programmes, KTU has diploma and certificate courses in business, engineering and science disciplines. KTU attracts both local and international students (KTU, 16 th Congregation \& Investiture Ceremony, 2020). The mission of KTU is poise to provide a special technical level of tertiary training through the advancement of career engrossed manpower in association with industry. KTU's core values are innovation. KTU is continuously looking for imaginative ways of doing better things, honesty and genuineness. KTU aims to become a vivacious institution of information as well as a reagent for change and pecuniary growth for Ghana (KTU, 16 th $^{\text {th }}$ Congregation \& Investiture Ceremony, 2020). 


\section{Research model}

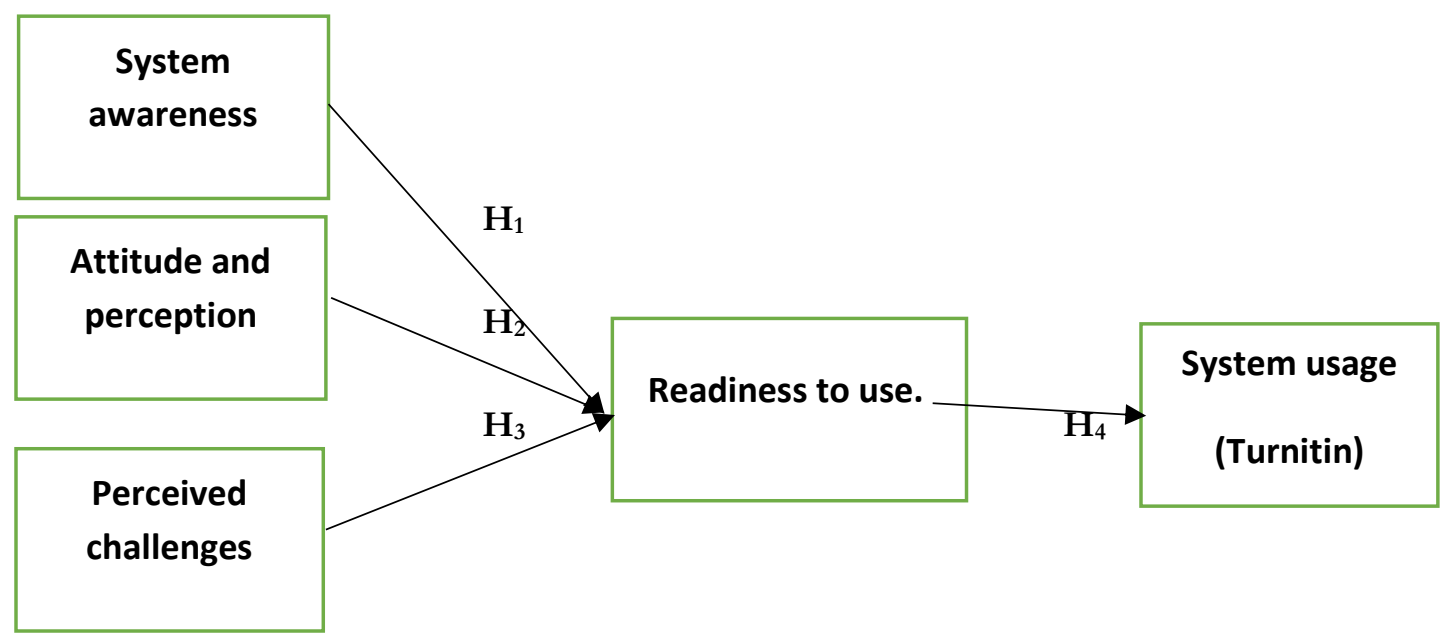

Figure 1: Authors construct, 2021

\subsection{Methodology}

Due to the COVID 19 outbreak, the researchers used google forms to design the questionnaire as per the objectives. The google forms questionnaire was shared through the institutional e-mails and the various Whatsapp platforms of the staff. A simple random technique was adopted for the current inquiry. The feedback was tracked through the same procedure and the results were extracted into the word format before the interpretation and analysis were done. Out of a staff population of four hundred and eighteen (418). Three hundred and thirteen (313) participated in the survey. After four weeks Three hundred and thirteen (313) protocols were retrieved out of the number distributed. Out of that four (4) were identified as improper for analysis because they were incomplete. A total number of three hundred and nine (309) protocols were properly completed. This represented a high acceptable response rate of $98.7 \%$. The explanatory design was functional to determine the connections amid the concepts to provide the understanding and a larger viewpoint of the perception of the use of the Turnitin Software in checking plagiarism among staff at Koforidua Technical University (KTU), Ghana.

Table 1: Definitions of operational terms of constructs and relationships linkages

\begin{tabular}{llll}
\hline Constructs & Definitions of operational terms & Sources and citations & $\begin{array}{l}\text { hypothesized } \\
\text { relationship }\end{array}$ \\
\hline $\begin{array}{llll}\text { System Awareness } \\
\text { (SA) }\end{array}$ & $\begin{array}{l}\text { System recognition, knowledge of } \\
\text { the operational \& functional } \\
\text { understanding. }\end{array}$ & (Forrester,1999; CSA, 2021) \\
$\begin{array}{llll}\text { Attitude } \\
\text { Perception (AP) }\end{array}$ & $\begin{array}{l}\text { Favourable \& unfavourable feelings } \\
\text { towards using the system }\end{array}$ & (Taylor\& Todd, 1995) & AP $\rightarrow \mathrm{RU}$ \\
& & & \\
\hline
\end{tabular}




\begin{tabular}{|c|c|c|c|}
\hline $\begin{array}{l}\text { Perceived } \\
\text { Challenges (PC) }\end{array}$ & $\begin{array}{l}\text { The degree to which a user believes } \\
\text { that using the system will be free of } \\
\text { struggle }\end{array}$ & $\begin{array}{l}\text { (Davis et. al, } \\
\text { 1989) }\end{array}$ & $\mathrm{PC} \rightarrow \mathrm{RU}$ \\
\hline $\begin{array}{l}\text { Readiness to Use } \\
\text { (RU) }\end{array}$ & $\begin{array}{l}\text { Notch to which a user believes that } \\
\text { using the system will enhance } \\
\text { performance. }\end{array}$ & $\begin{array}{l}\text { (Davis et. al, } \\
\text { 1989) }\end{array}$ & $\mathrm{RU} \rightarrow \mathrm{SU}$ \\
\hline
\end{tabular}

\subsection{Development of the research protocol}

The design of the survey protocol was directed by a proposal of Churchill in 1979 for planning a survey protocol (Bhattacherjee, 2012). The protocol was curved depending on the available works and the adjustment of prior items that have established substantial rationality in the ground of attitude and perception in the framework of Turnitin software (Bhattacherjee, 2012). The variables, namely, system awareness, attitude and perception, perceived challenges, readiness to use and system usage were controlled in the study. The study protocol was twofold. Section A was on the demographic characteristics of the respondents such as gender, age, highest educational qualification, department/unit and status. Section B was on the research models endogenous and exogenous. The items were dignified on a seven-point Likert scale. The items ranged from $1=$ 'strongly disagree' to $7=$ 'strongly agree'.

\subsection{Data collection and data analysis}

Google forms protocol was mailed to a sample of four hundred and eighteen (418) staff of Koforidua Technical in Ghana. The partakers filled the protocols and the answers were collected through emails. After four weeks of administering a total of three hundred and thirteen (313) were retrieved. Out of that four (4) were identified as inappropriate for analysis because they were incomplete. As a result, three hundred and nine (309) protocols were correctly completed, representing a highly acceptable response rate of 98.7\%. The partial Least Squares Structural Equation Model was used to analyze the data as a means of testing the model (Ashill, 2011).

\subsection{Results and Discussions}

In achieving the results discriminant validity, structural analysis and hypothesis testing assessment of the measurement model was assessed. Convergent validity is established when all indicators load highly on their assigned factors, for instance, 0.5 and above. As demonstrated in Table 2, the majority of the loadings of the factors were higher than the threshold expected (Hair, Black and Anderson, 2010). Again, an AVE value of the required value was obtained (0.5). This establishes that the constructs on average were good in the explanation of fifty percent of the variance of the pointers. In the same way in respect of reliability, the cutoff value of 0.7 was obtained (Hair $e t$ al., 2010). As verified from Table 3, the correlation values were less than the square root of AVE values, hence, suggestive of acceptable discriminant validity. 
Table 2: Discriminant validity assessment

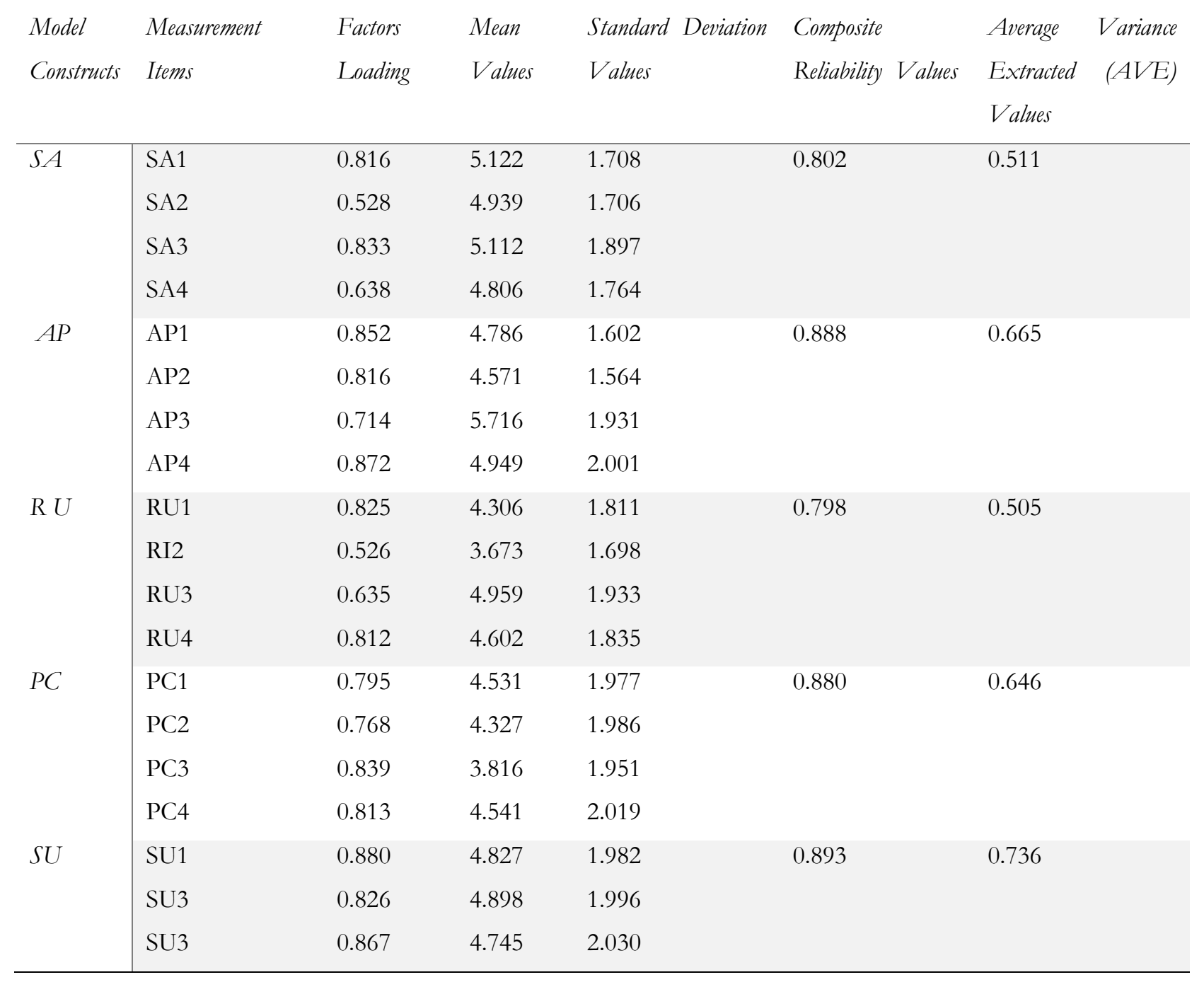

Table 3: Fornell-Larcker Criterion Discriminant Validity Assessment

\begin{tabular}{llllll} 
VARIABLES & AP & PC & RU & SA & SU \\
\hline AP & 0.816 & & & & \\
PC & 0.816 & 0.804 & & & \\
RU & 0.871 & 0.845 & 0.710 & 0.715 & \\
SA & 0.724 & 0.825 & 0.764 & 0.629 & 0.858 \\
SU & 0.823 & 0.779 & 0.814 & \\
\hline
\end{tabular}


Table 4: Results of Structural Model Analysis and Hypothesis Testing Validity Assessment

\begin{tabular}{lllllll}
\hline $\begin{array}{l}\text { Hypothesis } \\
\text { Paths }\end{array}$ & Relationships & $\begin{array}{l}\text { Standard } \\
\text { Paths } \\
\text { Coefficients }\end{array}$ & $\begin{array}{l}\text { Standard } \\
\text { Deviation } \\
\text { Values }\end{array}$ & $\begin{array}{l}\text { T-Statistics } \\
\text { Values }\end{array}$ & P-Value & Supported \\
\hline $\mathrm{H}_{1}$ & SA-RU & 0.126 & 0.109 & 1.158 & 0.247 & Not \\
& & & & & supported \\
$\mathrm{H}_{2}$ & AP-RU & 0.525 & 0.100 & 5.273 & 0.000 & Supported \\
$\mathrm{H}_{3}$ & PC-RU & 0.313 & 0.123 & 2.531 & 0.012 & Supported \\
\hline $\mathbf{H}_{4}$ & RU-SU & $\mathbf{0 . 8 1 4}$ & $\mathbf{0 . 0 3 6}$ & $\mathbf{2 2 . 6 7}$ & $\mathbf{0 . 0 0 0}$ & Supported \\
\hline
\end{tabular}

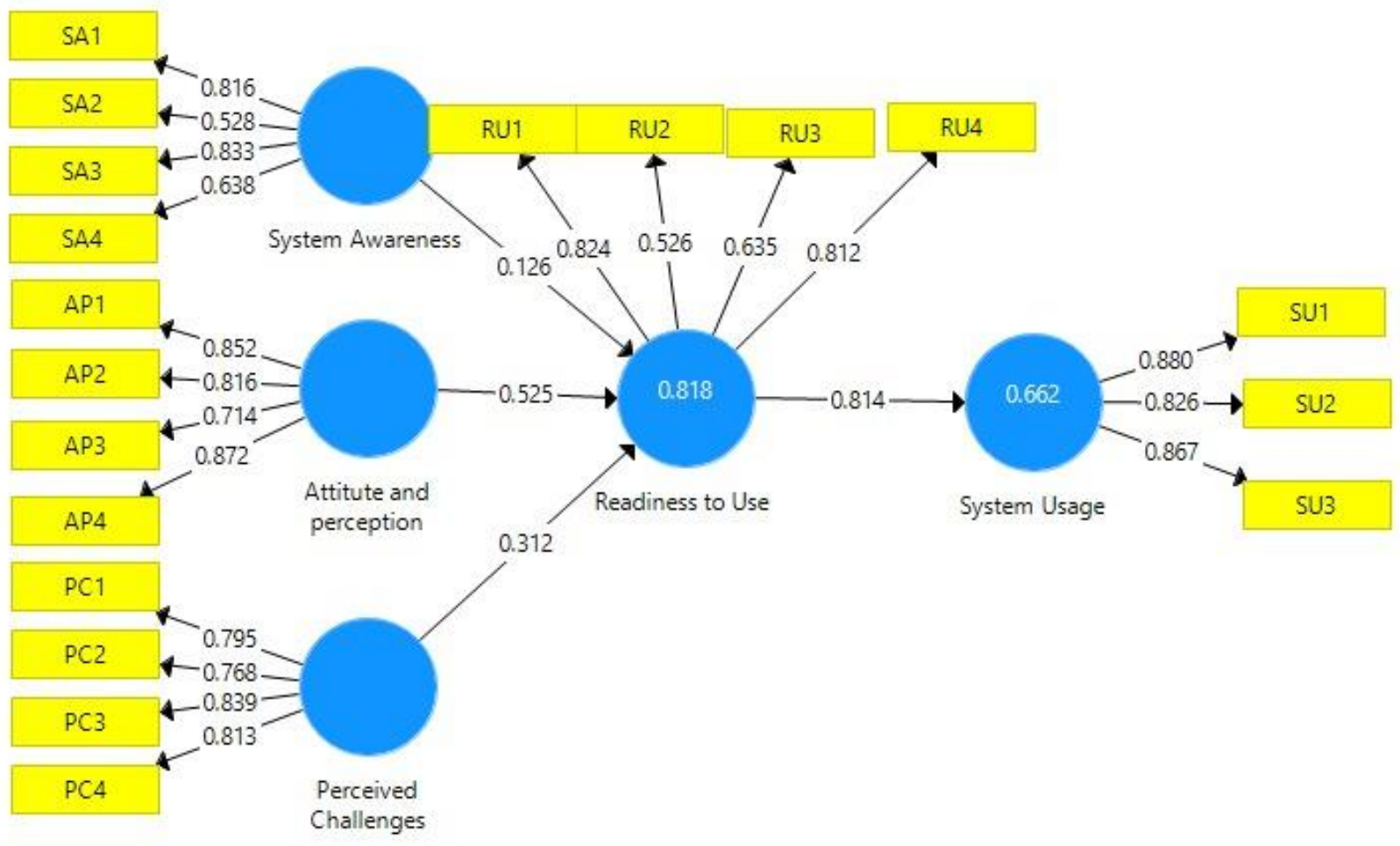

Figure 1: Patth estimation results

\subsection{Discussion}

The positive valuations respondents indicated positive signs of staff awareness of the Turnitin plagiarism detection software and its usefulness as a tool to generate authentic and genuine academic and research output. The results indicated high staff awareness in contrast to the report of Jereb et al. (2018) which revealed lack of awareness coupled with poor academic assistance as been the root causes of higher acts of plagiarism among researchers. It was clear from the results that albeit the staff were aware of the presence of the Turnitin plagiarism detection software on 
their campus, they had not done enough/avail themselves to get the needed information and training on effective usage of the system to their advantage. This problem may not be peculiar to the KTU as researchers (Helgesson \& Eriksson, 2015) in recent past have decried the issue of limited practical approaches and experiences among users on the use of the Turnitin software. This may explain why outcomes of the studies of some researchers (Olutola, 2016; Jereb et al., 2018) showed ascending rates of acts of plagiarism among staff and students of various universities. There is no doubt that academic dishonesty is on the ascendancy as identified by Olutola (2016), but more need to be done by university authorities to educated all especially academic staff on why academic dishonesty is both a moral and ethical issue, which needs to be avoided. This will help awaken the consciousness of academic staff towards the need to patronises the Turnitin plagiarism detection software to guard against possible acts of academic dishonesty

Readiness to Use recorded an $\mathrm{R}^{2}$ value of 0.818 . On the other hand, the dependent construct of the research model, thus System Usage attains an $\mathrm{R}^{2}$ value of 0.662 . The model explained that $81.8 \%$ in the variation of Readiness to Use thus the Turnitin Software and $66.2 \%$ variance of the System Usage thus Turnitin software. The implication is that the proposed model explains a $66.2 \%$ variance of the utilisation of the Turnitin Software by the staff of Koforidua Technical University.

Of all the four hypothesized relationships stated in this study, three of them were supported. As postulated in $\mathrm{H}_{1}$ System Awareness is not positively and significantly to Readiness to Use of a path coefficient of $\left(\beta=0.126^{* *}\right)$. The implication was that it does not support $\mathrm{H}_{1}$. This is different from the findings of Babalola (2012), whose study discovered a positive significant relationship between levels of plagiarism and awareness checking. Also, $\mathrm{H}_{2}$ states that Attitude and Perception positively affect Readiness to Use. This established path coefficient of $\left(\beta=0.525^{* *}\right)$. The results are in variance to that of Newton (2016), who explored the attitudes, ability, as well as confidence of users of a system and found a significant influence. Similarly, Perceived Challenges positively influence Readiness to Use having a path coefficient of $\left(\beta=0.313^{* * *}\right)$, supporting $\mathrm{H}_{3}$. The results did not conform to the previous conclusion of Bailey and Challen (2015) on a similar study. $\mathrm{H}_{4}$ correspondingly demonstrated a significant effect of Readiness to Use on System Usage. This was significant and supported by having a path coefficient of $\left(\beta=0.814^{* * *}\right)$. The results are in tangent to the previous finding of Rolfe (2011), which established that the use of Turnitin software had a significant impact on the writing skills of the user always.

\section{Conclusion}

The study researched the perception of Turnitin in checking plagiarism among staff at Koforidua Technical University, Ghana. All the measurement models were assessed. Correlation analysis was accomplished to institute an association between the variables. Both the reliability and discriminant validity tests were satisfactory. Three out of the four hypotheses tested shown a significant connection with the independent variables (Attitude and Perception, Perceived Challenges, Readiness to Use) and the dependent variable (System Usage) except System Awareness. The implication was that these variables dignified have a significant connection with System Usage thus the Turnitin Software except System Awareness. It suggests that the staff of KTU are using Turnitin Software to check the Plagiarism of their works. However, per the results, it is also clear that being aware of the system does not mean that 
it is been used by the staff hence the hypothesis that there is a relationship between System Awareness and Readiness to Use was rejected. The findings also revealed and confirmed that $81.8 \%$ are ready to use the Turnitin Software while $66.2 \%$ are using the Turnitin Software to check the Plagiarism of their work. This implies that there might be other factors that are accounting for the non-usage of the Turnitin Software. To attain $100 \%$ usage by the staff, there is the need for putting measures in place by management of the library.

\section{Recommendations}

Based on the findings of this research, the following recommendations were made:

$\checkmark \quad$ The University library should adopt more results-oriented measures to bring on board all staff to use the Turnitin Software. In this regard the university library should organize more training and workshops for the staff, refresher courses for new staff should be organized, having in place a dedicated phone to answer the questions of staff on Turnitin challenges, having real-time accounts on the library's website to give prompt answers to staff queries, among others

$\checkmark$ More system awareness/information/education is needed by the staff on the availability, relevance, and effective usage of the Turnitin plagiarism detection software.

$\checkmark$ System awareness is good but not enough to positively influence staff perceived ease of use of the system. Thus, the need to identify challenges staff face in using Turnitin in checking plagiarism. This, therefore, requires more training programmes to address all staff/user challenges of the system. More staff training on the effective use of Turnitin and education on practices that constitutes plagiarism is recommended to boost user confidence. optimum utilization of the Turnitin system requires positive user attitudes, skills, and confidence.

$\checkmark$ There is a need for reinforcement on the need for users/staff to get a common understanding of what constitutes plagiarism. There should be formal discussions with staff to highlight some significant differences in definitions of what constitutes 'commonly accepted knowledge' or disciplinary "jargons" which may be used without specific referencing or acknowledgement.

There is a need for an effective institutional policy on plagiarism and the use of the Turnitin antiplagiarism software in dealing with suspected plagiarism incidents.

\section{References}

Amin, M. Y. M., \& Mohammadkarimi, E. (2019). ELT students' attitudes toward the effectiveness of the anti-plagiarism software, Turnitin. Applied Linguistics Research Journal, 3(5), 63-75.

Anney, V. N., \& Mosha, M. A. (2015). Student's plagiarisms in higher learning institutions in the era of improved internet access: a a case study of developing countries. Journal of Education and Practice, 6(13), 203-216.

Babalola, Y.T., (2012). Awareness and incidence of plagiarism among undergraduates in a Nigerian private university. African Journal of Library, Archives \& Information Science, 22(1), 53-60.

Bennett, R., \& Kane, S. (2010). Factors associated with high first-year undergraduate retention rates in business departments with non-traditional student intakes. The International Journal of Management Education, 8(2), 53-66.

Botha, N. (2016). Plagiarism in masters and doctoral Studies. In postgraduate supervision: future foci for the knowledge society Stellenbosch, Sun Press. , 123-124 
Brown, N., \& Janssen, R. (2017). Preventing plagiarism and fostering academic integrity: A practical approach. Journal of Perspectives in Applied Academic Practice, 5(3), 102-109.

Bruton, S., \& Childers, D. (2016). The ethics and politics of policing plagiarism: a qualitative study of faculty views on student plagiarism and Turnitin. Assessment \& Evaluation in Higher Education, 41(2), 316-330.

Buckley, C., Picking, R. \& Grout, V., (2008). Internet plagiarism: A survey and case study. In Proceedings of the Fourth Collaborative Research Symposium on Security, E-learning, Internet and Networking, Glyndwr University, Wrexham, 6-7 November 2008 (p. 56).

Center for System Awareness (CSA, 2021). Available at https://www.systemsawareness.org

Cheema, Z.A., Mahmood, S.T., Mahmood, A. \&| Shah, M.A., (2011). Conceptual awareness of research scholars about plagiarism at higher education level: Intellectual property right and patent. International Journal of Academic Research, 3(1), $666-671$.

Davis, F.D. (1989). Perceived usefulness, perceived ease of use, and user acceptance of information $\quad$ technology. MIS Quarterly 13(3): 319-340.

Davis, F.D. (1993). User acceptance of information technology: system characteristics, user perceptions and behavioral impacts. International Journal of Man-Machine Studies 38: 475- 487.

Davis, F.D., R.P. Bagozzi, and P.R. Warshaw (1989). User acceptance of computer technology: A comparison of two theoretical models." 35(8): 982-1003.

Dawson, M.M. \& Overfield, J.A., (2006). Plagiarism: Do students know what it is? Bioscience Education, 8(1), 1-15.

Deubel, P. (2018). Punishment or policy change: A case of plagiarism in a dissertation. Joumal of Educational Research and Practice, 8(1), 8.

Dreuth Z, L., Steen, J. A., \& Metz Z, N. (2011). Originality detection software in a graduate policy $\quad$ course: a mixedmethods evaluation of plagiarism. Journal of Teaching in Social Work, 31(4),

Ferro, M. J., \& Martins, H. F. (2016). Academic plagiarism: yielding to temptation. Journal of Education, Society and Behavioural Science, 13(1), 1-11.

Gilmore, J., Strickland, D., Timmerman, B., Maher, M. \& Feldon, D., (2010). Weeds in the flower $\quad$ garden: An exploration of plagiarism in graduate students' research proposals and its connection to enculturation, ESL, and contextual factors. International Journal for Educational Integrity, 6(1), 13 - 28.

Helgesson, G., \& Eriksson, S. (2015). Plagiarism in research. Medicine, Health Care and Pbilosophy, 18(1), $\quad$ 91-101.

Hosny, M. and Fatima, S., (2014). The attitude of students towards cheating and plagiarism: University case study. Journal of Applied Sciences, 14(8), 748-757.

Ibegbulam, I.J. and Eze, J.U., (2015) Knowledge, perception, and attitude of Nigerian students to ～～plagiarism: A case study. IFLA Journal, 41(2), 120-128.

Ison, D.C., 2012. Plagiarism among dissertations: Prevalence at online institutions. Journal of Academic $\quad$ Ethics, 10(3), 227236.

Jereb, E., Perc, M., Lämmlein, B., Jerebic, J., Urh, M., Podbregar, I., \& Šprajc, P. (2018). Factors influencing plagiarism in higher education: A comparison of German and Slovene students. PloS one, 13(8), e0202252.

Jones, K. O., \& Moore, T. A. (2010). Turnitin is not the primary weapon in the campaign against plagiarism. In Proceedings of the 11th International Conference on Computer Systems and Technologies and Workshop for PhD Students in Computing on International Conference on Computer Systems and Technologies (pp. 425-429). 
Jones, K. O. (2008, June). Practical issues for academics using the Turnitin plagiarism detection software. In Proceedings of the 9th International Conference on Computer Systems and Technologies and Workshop for PhD Students in Computing (pp. IV-1).

Kumar, A. and Mohindra, R., (2018). Conceptual awareness and attitude of law research scholars towards plagiarism: a study of Panjab University, Chandigarh. In Proceedings of the International Conference on Digital Transformation (ICDT 2018), National Law University, Delhi, 29. 712-26).

Kumari, M.P. and Lakshmi, S., (2015). Awareness on plagiarism among research scholars of Sri Venkateswara University: a study. IOSR Journal of Humanities and Social Science, 20(3), 55-59.

Mohindra, R. (2019). Exploring awareness and attitude on plagiarism among research Scholars: A case study of Panjab University, Chandigarh (India). Library Philosophy and Practice (e-Journal). 2551.

Newton, P., 2016. Academic integrity: A quantitative study of confidence and understanding in students at the start of their higher education. Assessment \& Evaluation in Higher Education, 41(3), $\quad$ 482-497.

Ocholla, D. N., \& Ocholla, L. (2016). Does open access prevent plagiarism in higher education? African Journal of Library, Archives, and Information Science, 26(2), 189-202.

Olutola, F. O. (2016). Towards more enduring prevention of scholarly plagiarism among university $\quad$ students in Nigeria. African Journal of Criminology and Justice Studies, 9(1), 83-97.

Onuoha, U.D., Unegbu, V.E., Ikonne, C.N. and Madukoma, E., (2013). Using online reference tools to combat plagiarism in higher institutions in Nigeria. Development, 4(8). 50-57.

management

Ramzan, M., Munir, M. A., Siddique, N., \& Asif, M. (2012). Awareness about plagiarism amongst $\quad$ university students in Pakistan. Higher Education, 64(1), 73-84.

Rodchua, S. (2017). Effective tools and strategies to promote academic integrity in e-learning. International Journal of eEducation, e-Business, e-Management, and e-Learning, 7(3), 168.

Ryan, G., Bonanno, H., Krass, I., Scouller, K. \& Smith, L., (2009). Undergraduate and postgraduate $\quad$ pharmacy students' perceptions of plagiarism and academic honesty. American Journal of Pharmaceutical Education, 73(6).

Shava, F. B., \& Gamundani, A. M. (2014). A user awareness model for averting computer threats.

Singh, N., (2017). Level of awareness among veterinary students of GADVASU towards plagiarism: a case study. The Electronic Library. 899 - 915

Taylor, S., \& Todd, P. A. (1995). Understanding information technology usage: A test of competing models. Information systems research, 6(2), 144-176.Park, C., 2003. In other (people's) words: Plagiarism by university students--literature and lessons. Assessment \& Evaluation in Higher $\quad$ Education, 28(5), 471-488.

Thomas, D. (2017). Factors that explain academic dishonesty among university students in

Thailand. Ethics

$\nLeftarrow$ Behavior, 27(2), 140-154.

Turnitin, L. L. C. (2017). Turnitin.

Vanbaelen, R. \& Harrison, J., (2013). Plagiarism awareness. In IEEE International Professional Communication

2013 Conference (1-8). 